\title{
Natural Color Changes of Silk Fabrics by Leaves of Castanea crenata and Artemisia capillaris with Mordants
}

\author{
Suk-Yul Jung \\ Department of Biomedical Laboratory Science, Molecular Diagnosis Research Institute, \\ Namseoul University, 31020 Chungnam, Republic of Korea
}

\begin{abstract}
Castanea crenata, known as Korean chestnut has been used as a cosmetic material due to its anti-wrinkle and anti-aging effects. Artemisia capillaris is well known as famous Traditional Chinese Medicine (TCM) for treating acute and chronic hepatitis in China. In this study, the leaves of C. crenata and A. capillaris were applied as natural dyes. In addition, the color patterns were compared by the pre-mordanting, that is onchrome to silk fabric. Silk fabric was shown colors close to white by $A$. capillaris without any mordant and with sodium tartrate plus citric acid. Interestingly, iron (II) sulfate and potassium dichromate induced green as compared with other mordants inducing yellow or white. The composition of iron could induce very different color changes. This study would be useful to obtain color changes by the leaves of C. crenata and A. capillaris for some materials, e.g., cotton. Further study will be processed to evaluate them as a biological usage.
\end{abstract}

Key words: Castanea crenata, Artemisia capillaris, silk fabric, mordant, color change, leaves

\section{INTRODUCTION}

Castanea crenata, known as Korean chestnut (Falk, 2003) is a small to medium-sized deciduous tree growing to $10-15 \mathrm{~m}$ tall and its leaves are $8-19 \mathrm{~cm}$ long and $3-5 \mathrm{~cm}$ broad. The chestnut tree has a lot of biological effects of which it has been used as a cosmetic material due to its anti-wrinkle and anti-aging effects (Noh et al., 2010). Even if it has a lot of biological roles, the chestnut and its tree has no report to be applied for staining as dye.

Artemisia (Sunset Books, 1995) is a large, diverse genus of plants with between 200 and 400 species belonging to the daisy family Asteraceae. A. capillaris is well known as famous Traditional Chinese Medicine (TCM) for treating acute and chronic hepatitis in China (Geng et al., 2018). However, it has not been reported that A. capillaris would be applied for staining dye for fabrics or other biological tissues.

The term, natural dye, covers all the dyes derived from natural resources such as plants, insects and animals (Sharma and Grover, 2011). The natural dyes are vegetable dyes from plant sources-roots, fruits, coats, leaves and wood. Mordant is used to help natural dyeing (Jung, 2018; Park and Jung, 2014). Mordants include tannic acid, alum, chrome alum and certain salts of aluminium, chromium, copper, iron, potassium, etc. Moreover, the mordants can change and obtain other colors (Jung, 2018;
Park and Jung, 2014). For example, copper acetate induced very different colors of khaki to silk fiber (Jung and Park, 2014).

In this study, the leaves of C. crenata and A. capillaris were applied as natural dyes. In addition, the color patterns were compared by the pre-mordanting that is onchrome to silk fabric.

\section{MATERIALS AND METHODS}

Preparation of natural dyes from the leaves of $C$. crenata and $A$. capillaris: The leaves of were purchased from a traditional market and washed three times with Distilled Water (DW). The $700 \mathrm{~g}$ of each material was completely dried on air for the next extraction of dye. Briefly, the dried each material was dissolved into $7 \mathrm{~L}$ of DW by boiling with strong flame. For the leaves of C. crenata, $\mathrm{pH} 4.0$ was continuously maintained and boiling to completely extract the natural dye was performed for $40 \mathrm{~min}$. For A. capillaris, $\mathrm{pH} 4.0$ was continuously maintained and other steps are done like the leaves of C. crenata. They were filtered to obtain the pure dye for all natural staining.

Staining of silk fabric by the leaves of $C$. crenata and $A$. capillaris: Our research targeted the staining of silk fabirc using the leaves of C. crenata and A. capillaris and changes of silk colors using a variety of mordants. Mordants of copper acetate, aluminum potassium sulfate, 
sodium tartrate plus citric acid, iron (II) sulfate or potassium dichromate were pre-mordanted with the fabric silk as shown in Table 1 and then, the dye was added. The dyeing time was about $40 \mathrm{~min}$. After the dyeing was finished, the silk fabric was washed with water and dried without squeezing.

\section{Table 1: Treatment of mordants to silk fabric}

\begin{tabular}{lccc}
\hline Mordants & $\begin{array}{c}\text { Volume of } \\
\text { mordants }(\mathrm{g})\end{array}$ & $\begin{array}{c}\text { Volume of distilled } \\
\text { water (mL) }\end{array}$ & $\begin{array}{c}\text { Treatment } \\
\text { time (min) }\end{array}$ \\
\hline $\begin{array}{l}\text { Copper acetate } \\
\begin{array}{l}\text { Aluminum potassium } \\
\text { sulfate }\end{array}\end{array}$ & 10 & 600 & 15 \\
$\begin{array}{l}\text { Sodium tartrate plus } \\
\text { citric acid }\end{array}$ & $30+90$ & 600 & 15 \\
$\begin{array}{l}\text { Iron (II) sulfate } \\
\text { Potassium dichromate }\end{array}$ & 20 & 600 & 15 \\
\hline
\end{tabular}

(a)

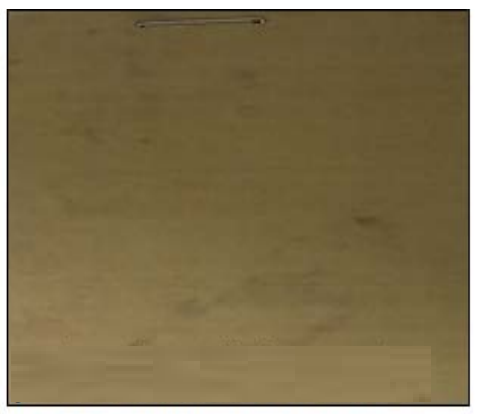

(c)

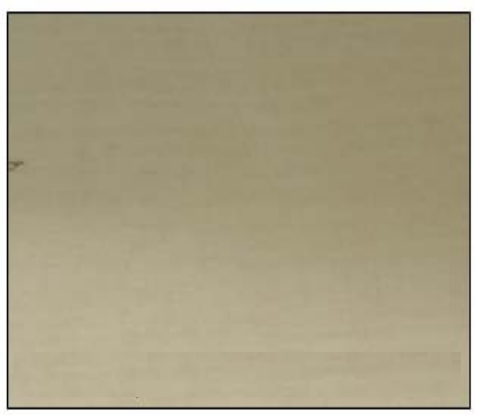

(e)

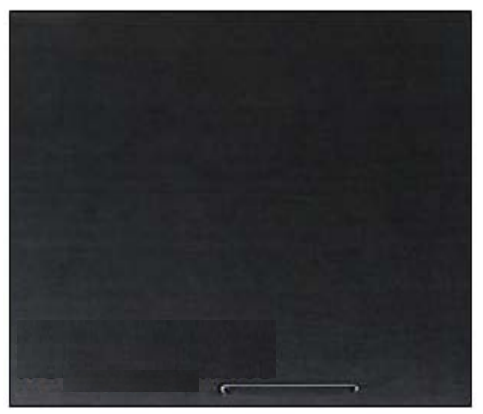

\section{RESULTS AND DISCUSSION}

Staining of silk fabric by the leaves of $C$. crenata: The plants of C. crenata-leaves and A. capillaris have no common point but with regards of natural staining, they all show clear green. Here, the staining colors were analyzed by the dyes and mordants. The dye extracted from the C. crenata leaves induced yellowish color to the silk fabric. If the dyeing time was long, it would have become more yellowish (data not shown). Except for aluminum potassium sulfate inducing color close to white, copper acetate, sodium tartrate plus citric acid, iron (II) sulfate and potassium dichromate induced colors close to yellow but it was found to only have lightness or darkness (Fig. 1).

(b)

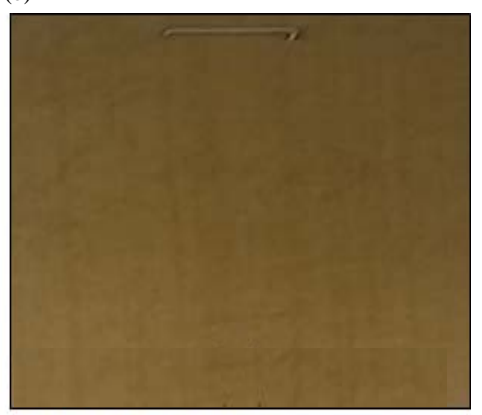

(d)

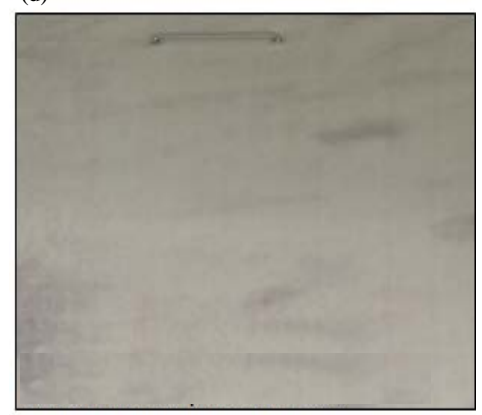

(f)

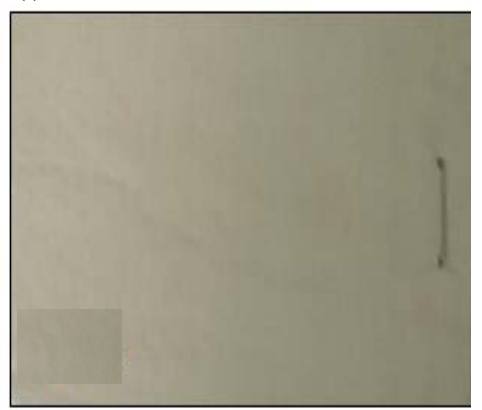

Fig. 1: Natural staining of silk fabric by the treatment of mordants followed by the leaves of Castanea crenata: a) Potassium dichromate; b) Copper acetate; c) Aluminum potassium sulfate; d) Sodium tartrate plus citric acid; e) Iron (II) sulfate and f) None 
(a)

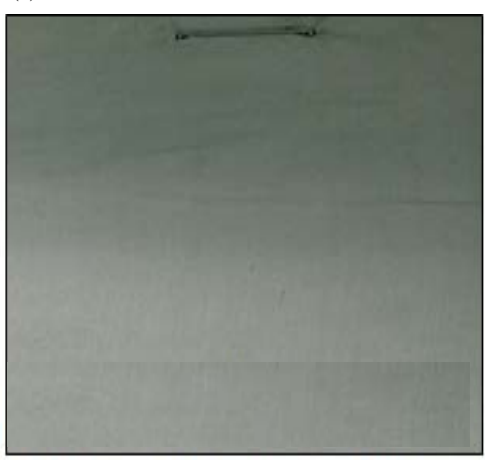

(c)

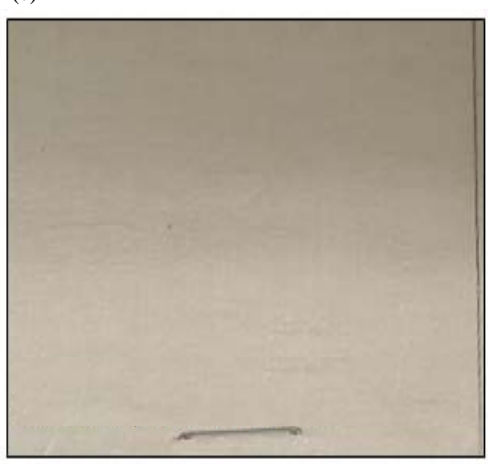

(e)

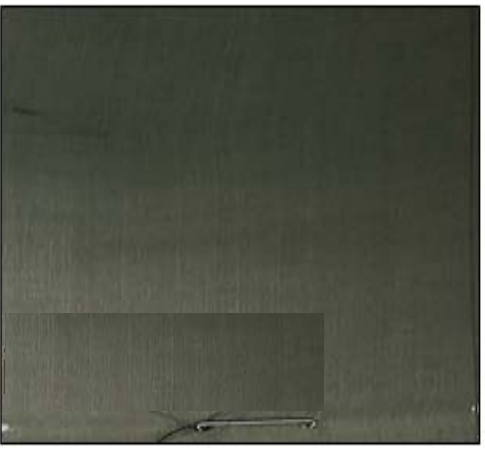

(b)

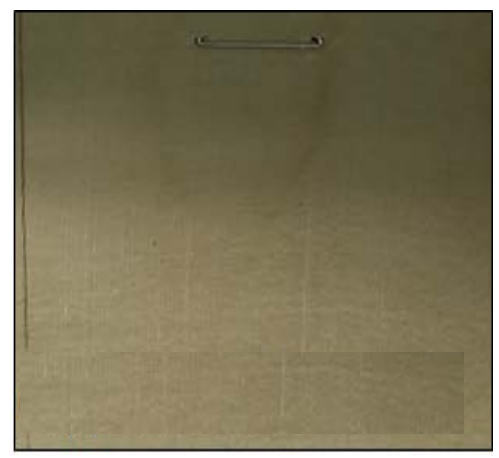

(d)

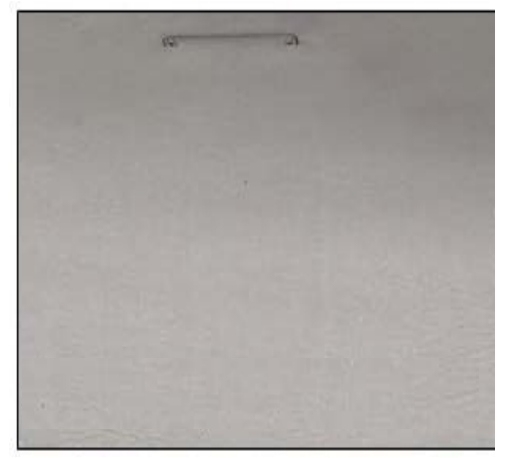

(f)

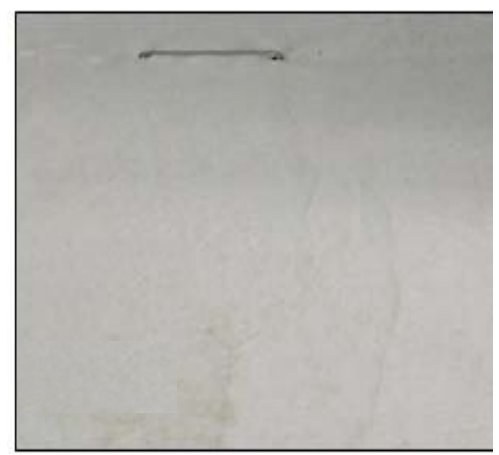

Fig. 2: Natural staining of silk fabric by the treatment of mordants followed by Artemisia capillaris: a) Potassium dichromate; b) Copper acetate; c) Aluminum potassium sulfate; d) Sodium tartrate plus citric acid; e) Iron (II) sulfate and f) None

Staining of silk fabric by the leaves of $A$. capillaris: As shown in Fig. 1, the leaves of C. crenata were associated with inducing yellowish color as a natural dye. Here, to understand the use of $A$. capillaris as a natural dye, silk fabric was applied for the staining with the mordants as mentioned at materials and methods. Silk fabric was shown colors close to white by $A$. capillaris without any mordant and with sodium tartrate plus citric acid (Fig. 2). Copper acetate and aluminum potassium sulfate induced yellowish color but copper acetate did darker yellow (Fig. 2). Interestingly, iron (II) sulfate and potassium dichromate induced green as compared with other mordants inducing yellow or white (Fig. 2).

It is well known that natural dyes are not harmful to the environment and specifically are good to human body. Due to the eco-friendly advantages, the demand for natural dyes is increasing day by day (Ali et al., 2009; Guinot et al., 2008). These properties would be emphasized nowadays which may prevent allergy and other diseases. Therefore, natural dyes must be good materials alternative to synthetic chemical dyes. This 
Table 2: Percent of relative comparison of color change as compared with original color stained by Castanea crenata* and Artemisia copillaris ${ }^{* *}$

\begin{tabular}{lccccc}
\hline Without mordant & Copper acetate & Aluminum potassium sulfate & Sodium tartrate plus citric acid & Iron (II) sulfate & Potassium dichromate \\
\hline $100^{*}$ & $80^{*}$ & $90^{*}$ & $50^{*}$ & $10^{*}$ & $80^{*}$ \\
$100^{* *}$ & $60^{* *}$ & $70^{* *}$ & $90^{* *}$ & $20^{* *}$ & $50^{* *}$ \\
\hline
\end{tabular}

study provided information about the application of the leaves of C. crenata and $A$. capillaris as natural dyes and also color changes by the pre-mordanting method.

Percent of relative comparison of color change as compared with original color stained by $C$. crenata and $A$. capillaris: The staining of the silk fabric by the leaves of $C$. crenata and $A$. capillaris was performed with $\mathrm{pH} 4.0$ in the staining solution. In addition to gross findings on Fig. 1 and 2, the analysis of color changes was done by numerical percentage values in Table 2. Iron (II) sulfate induced the most different color changes as compared with original color of no mordant. On the other hand, copper acetate and aluminum potassium sulfate induced very similar color changes. Taken together, it implied that the composition of iron could induce very different color changes.

\section{CONCLUSION}

Even though the leaves of $C$. crenata and A. capillaris did not have many common characteristics, they induced very similar color changes by the extracted dyes and mordants. Very interestingly, iron (II) sulfate could induce very dark color changes of green or brown. Overall, it implied that the leaves of C. crenata and $A$. capillaris would be useful to get yellow and green, respectively. As mentioned in introduction, Haematoxylin is widely used to stain tissues with a counterpart of eosin as an eco-friendly component (Mirjalili et al., 2011). Haematoxylin is also a dye extracted from a natural product for biological usage. This study would be useful to obtain color changes by the leaves of C. crenata and A. capillaris for some materials, e.g., cotton. Further study will be processed to evaluate them as a biological usage.

\section{RECOMMENDATIONS}

Our study would be useful to comparatively analyze the staining changes by the leaves of $C$. crenata and A. capillaris. Further study will be processed to evaluate them as a biological usage and other applications of natural staining.

\section{ACKNOWLEDGEMENT}

Funding for this study was provided by Namseoul University.

\section{REFERENCES}

Ali, S., T. Hussain and R. Nawaz, 2009. Optimization of alkaline extraction of natural dye from Henna leaves and its dyeing on cotton by exhaust method. J. Cleaner Prod., 17: 61-66.

Falk, B., 2013. The Resilient Farm and Homestead: An Innovative Permaculture and Whole Systems Design Approach. Chelsea Green Publishing Company, Hartford, Vermont, USA., ISBN:978-1-60358-444-9, Pages: 312.

Geng, C.A., T.H. Yang, X.Y. Huang and J. Yang et al., 2018. Anti-hepatitis B virus effects of the traditional Chinese herb Artemisia capillaries and its active enynes. J. Ethnopharmacol., 224: 283-289.

Guinot, P., A. Gargadennec, G. Valette, A. Fruchier and C. Andary, 2008. Primary flavonoids in marigold dye: Extraction, structure and involvement in the dyeing process. Phytochem. Anal. Intl. J. Plant Chem. Biochem. Techn., 19: 46-51.

Jung, S.Y. and S. Y. Park, 2014. Applicable natural staining by Sophora japonica L. and Phellodendron amurense ruprecht. Intl. J. Appl. Eng. Res., 9: $18215-18222$.

Jung, S.Y., 2018. Natural Staining of the Coat of Allium cepa L. and leaf of Camellia sinensis var. assamica to a silk fabric. J. Eng. Appl. Sci., 13: 2492-2495.

Mirjalili, M., K. Nazarpoor and L. Karimi, 2011. Eco-friendly dyeing of wool using natural dye from weld as co-partner with synthetic dye. J. Cleaner Prod., 19: 1045-1051.

Noh, J.R., G.T. Gang, Y.H. Kim, K.J. Yang and J.H. Hwang et al., 2010. Antioxidant effects of the chestnut (Castanea crenata) inner shell extract in t-BHPtreated HepG2 cells and $\mathrm{CCl}_{4}$-and high-fat diet-treated mice. Food Chem. Toxicol., 48: 3177-3183.

Park, S.Y. and S.Y. XJung, 2014. Technical approaches of a natural dye extracted from Phytolacca Americana L.-berries with chemical mordants. Technol. Health Care, 22: 339-343.

Sharma, A. and E. Grover, 2011. Color fastness of walnut dye on cotton. Indian J. Nat. Prod. Resour., 2: 164-169.

Sunset Books, 1995. Sunset Western Garden Book. 6th Edn., Sunset Publishing Corporation, Oakland, CA., USA., ISBN: 9780376038517, pp: 606-607. 